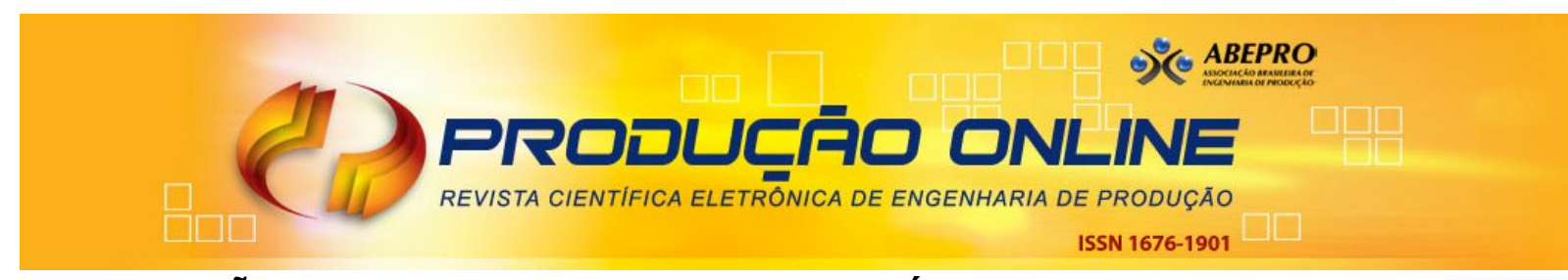

\title{
APLICAÇÃO DO SCRUM EM SERVIÇOS: ANÁLISE EM UMA FABRICANTE DE AERONAVES
}

\section{SCRUM APPLICATION IN SERVICE: ANALYSIS ON AN AIRCRAFT MANUFACTURER}

\author{
Stefano Petrini de Oliveira* spetrini@outlook.com \\ Jorge Muniz Junior* jorgemuniz@feg.unesp.br \\ *Universidade Estadual Paulista, UNESP, Guratinguetá, SP
}

\begin{abstract}
Resumo: Este artigo analisa a aplicação da abordagem Scrum em uma área de serviço de ensaios em aeronaves. Trata-se de um estudo qualitativo realizado na maior fabricante de aeronaves do Brasil. Scrum é amplamente utilizado na gestão de projetos de softwares em diversos segmentos, porém suas características permitem a utilização na gestão de projetos em geral, tanto aplicações no desenvolvimento de produtos quanto serviços. Este trabalho contribui ao analisar a aplicação para serviços e ilustra a utilização do Scrum para gestores. Aborda-se a implantação, o amadurecimento, empecilhos encontrados e resultados alcançados com o uso do Scrum. O setor analisado é o de Ensaios de Sistemas Hidromecânicos e Comandos de Voo, responsável por realizar testes de sistemas em laboratórios compostos por partes reais e partes que simulam os sistemas das aeronaves. Obtiveram-se dados descritivos mediante contato direto com a situação alvo. Buscou-se informação diretamente com os integrantes da equipe ensaios, utilizando um questionário como instrumento de pesquisa. A aplicação da abordagem ágil Scrum no gerenciamento de projetos trouxe bons resultados a esta área de Ensaios, posteriormente, às divisões relacionadas e metas da organização. Alcances de natureza organizacional da gerência e equipe, maior eficiência de processamento e conclusão de metas próximo do previsto foram alcançados. O Scrum trouxe transparência, pois investiu em maior visibilidade dos aspectos significativos do processo para todos aqueles relacionados. Auxiliou em inspeções e monitoramento de resultados, promovendo acompanhamento e orientação do processo em direção ao objetivo e detectando indesejáveis variações e empecilhos durante a campanha de testes.
\end{abstract}

Palavras-chave: Abordagem ágil. Scrum. Desenvolvimento de Produtos. Serviço. Fabricante Brasileira de Aeronaves.

Abstract: This article analyzes the application of Scrum approach in a test service area in aircraft. It is a qualitative study conducted at the largest aircraft manufacturer in Brazil. Scrum is widely used for software project management in several segments, but its features allow the use in project management in general applications, both development of products and services. This paper contributes to analyze the application for services and illustrates the Scrum use for managers. It explains the establishment, maturation, obstacles encountered and results achieved with the Scrum. The sector analyzed is the Hydro-Testing Systems and Controls Flight, responsible for performing system testing in laboratories composed of real parts and simulating systems of aircraft parts. Descriptive data were obtained through direct and interactive contact with the target situation. We sought information with the team members of testing using a questionnaire as a research tool. The application of agile approach Scrum in project management has brought good results for this testing area, subsequently for the related divisions and organization goals. It reached a better organization of management and staff, greater processing efficiency and completion targets were achieved close to that predicted. Scrum has brought transparency, since invested in increased visibility of the significant aspects of the process for all those listed. It assisted the inspections and monitoring results, propelling the guiding the process toward the goal and detecting undesirable variations and obstacles during the test campaign.

Keywords: Agile Approach. Scrum. Product Development. Service. Brazilian Aircraft Manufacturer. 


\section{INTRODUÇÃO}

O Scrum é uma abordagem iterativa e incremental para gestão de projetos que visa tornar os processos ágeis e flexíveis, promovendo a transparência, inspeção e adaptação do projeto (NONAKA e TAKEUCHI, 1986). A partir da comunicação aprimorada, os membros da equipe são capazes de manipular mudanças repentinas nos requisitos, aumentando a previsibilidade e o controle de riscos do projeto (INAYAT et al., 2012; CARVALHO et al., 2012).

Scrum é amplamente utilizado na gestão de projetos de softwares em diversos segmentos, tais como: armazenamento de dados (KALLLINEY, 2009; TSAI et al., 2014), plataformas online (WILLEKE, 2009), área da saúde (LONG, STARR, 2008), militar, financeiro, setores públicos (JAKOBSEN e JOHNSON, 2008). É usado de forma a encadear o desenvolvimento em uma sequência de atividades, na qual a equipe contribui com seu trabalho no formato de atributos e funcionalidades que incrementam o projeto a cada iteração.

As características desta abordagem permitem sua utilização na gestão de projetos em geral. Como em aplicações no desenvolvimento de produtos, tais como: setor espacial (HUANG et. al., 2012), biotecnologia (ROTTLER e RODRIGUES, 2008), mídia e comunicação (JUDY e KRUMMINS-BEANS, 2007). Identificam-se também trabalhos em gestão de projetos para serviços, dentre eles: plataforma como serviço (PaaS), software como serviço (SaaS) (MENCKE, 2008; SINGH. 2008), serviço de treinamento a desenvolvedores (THERRIEN e LEBEL, 2009), companhia de avaliação de veículos (UY e ROSENDAHL, 2008).

A integração do capital humano, financeiro, tempo, escopo de atividades, comunicação, riscos pertinentes, qualidade dos processos e resultados exigem atenção para o gerenciamento em novos projetos, seja quais forem: software, produto ou serviço. Logo, mapear o processo de desenvolvimento, monitorar o programa, indicar desempenho e rendimento dos personagens e atributos envolvidos fazem parte da estratégia gerencial e devem manter um enfoque sistêmico e integrado, produzindo efeitos benéficos e sustentáveis para área. 
Este artigo analisa a aplicação do Scrum em uma área de serviço de ensaios em aeronaves. Trata-se de um estudo qualitativo realizado na maior fabricante de aeronaves do Brasil.

Aborda-se a implantação, o amadurecimento, empecilhos encontrados e resultados alcançados com o uso do Scrum. O setor analisado é a de Ensaios de Sistemas Hidromecânicos e Comandos de Voo, responsável por realizar testes de sistemas em laboratórios compostos por partes reais e partes que simulam os sistemas das aeronaves. Relativo a criação, execução e análise de resultados de roteiros de testes (RT's) dos sistemas pneumáticos, elétricos, de instrumentos, de combustível, de ar condicionado, pressurização, entre outros. Ao fim desta etapa, o valor agregado pelo setor corresponde à maturidade do produto final, e uma série de resultados, já analisados, segue para a aprovação da Engenharia de Produto.

A utilização do Scrum neste setor da empresa permitiu maior visibilidade do processo, agilidade do comprimento de metas e coordenação das tarefas a serem executadas; porém, a operação requisitou esforço e foco da equipe durante a fase de implantação. Este trabalho contribui ao analisar a aplicação para serviços, não tão tradicional na literatura quanto softwares e produtos; e ilustra a utilização do Scrum para gestores.

A seção 2 apresenta os conceitos de desenvolvimento de produtos, o Scrum e o panorama bibliográfico destes temas. A seção 3 trata do Procedimento Metodológico e apresenta o resultado da pesquisa de campo. A seção 4 aborda a Análise de Resultados. Finalmente, na última seção estão as considerações finais sobre o estudo realizado, encabeçadas pela Conclusão.

\section{SCRUM}

Segundo Armstrong (2007) produto é um conjunto de atributos, tangíveis e intangíveis, constituídos através de um processo de produção. É oferecido ao mercado para sua atenção, aquisição, uso ou consumo e que deve satisfazer a um desejo ou necessidade. Em seguida, Keller e Kotler (2012) definem serviço como qualquer ato ou desempenho, essencialmente intangível, que uma parte pode 
oferecer à outra e não resultando em sua propriedade. A execução de um serviço pode estar ou não ligada a um produto concreto.

Oito etapas são propostas por Kotler (2000) para o processo de desenvolvimento de novos produtos: geração de ideias, seleção de ideias, desenvolvimento e teste de conceito, desenvolvimento da estratégia de marketing, análise do negócio, desenvolvimento do produto, testes de mercado e comercialização. O objetivo de cada etapa é determinar se a ideia deve ser abandonada ou se deve prosseguir para a etapa seguinte

Os serviços de ensaios e testes, realizados na etapa de desenvolvimento do produto, destinam-se a: verificação de funcionalidades, documentação, atendimento aos requisitos, às normas, obtendo-se desta forma uma validação e certificado de homologação. Normalmente, tais ensaios são de naturezas funcionais, materiais, projeto de parâmetros, testes acelerados, ambientais, de confiabilidade, de manutenção, pré-envelhecimento e de durabilidade.

Independente do objeto da gestão de desenvolvimento, o Scrum visa promover um modelo de auto-organização da equipe, aonde todos são responsáveis pela qualidade; além de fornecer maior visibilidade e melhores níveis de detalhamento (MOE et al., 2012; GRIMHEDEN e EDIN, 2013), transparência em decisões e acompanhamento dos processos (VLAANDEREN et al., 2011; MARCHI e GROVE, 2009).

Scrum é uma abordagem que promove a agilidade na gestão de requisitos, validação, feitura de relatórios e métricas de desempenho (ROTTIER e RODRIGUES, 2008) condiciona a equipe para mudanças repentinas de metas, demandas gerenciais (KETTUNEN, P., 2009) e estimula a normalização e convergência de práticas de desenvolvimento (CHEN, 2010).

Huang et al. (2013) inclui que a gestão de projeto com ações integradas necessita de que cada membro e líder de equipe tenham não só autoridade e responsabilidade pelo seu subsistema, mas também, pela interface e interações com todos os subsistemas, propondo assim, modelos integrados de Scrum entre as esquipes. Ressalta-se a importância dos processos e eventos de revisão, afim de fornecer novas entradas ao processo 
Os elementos de ação do Scrum são ilustrados na Figura 1.

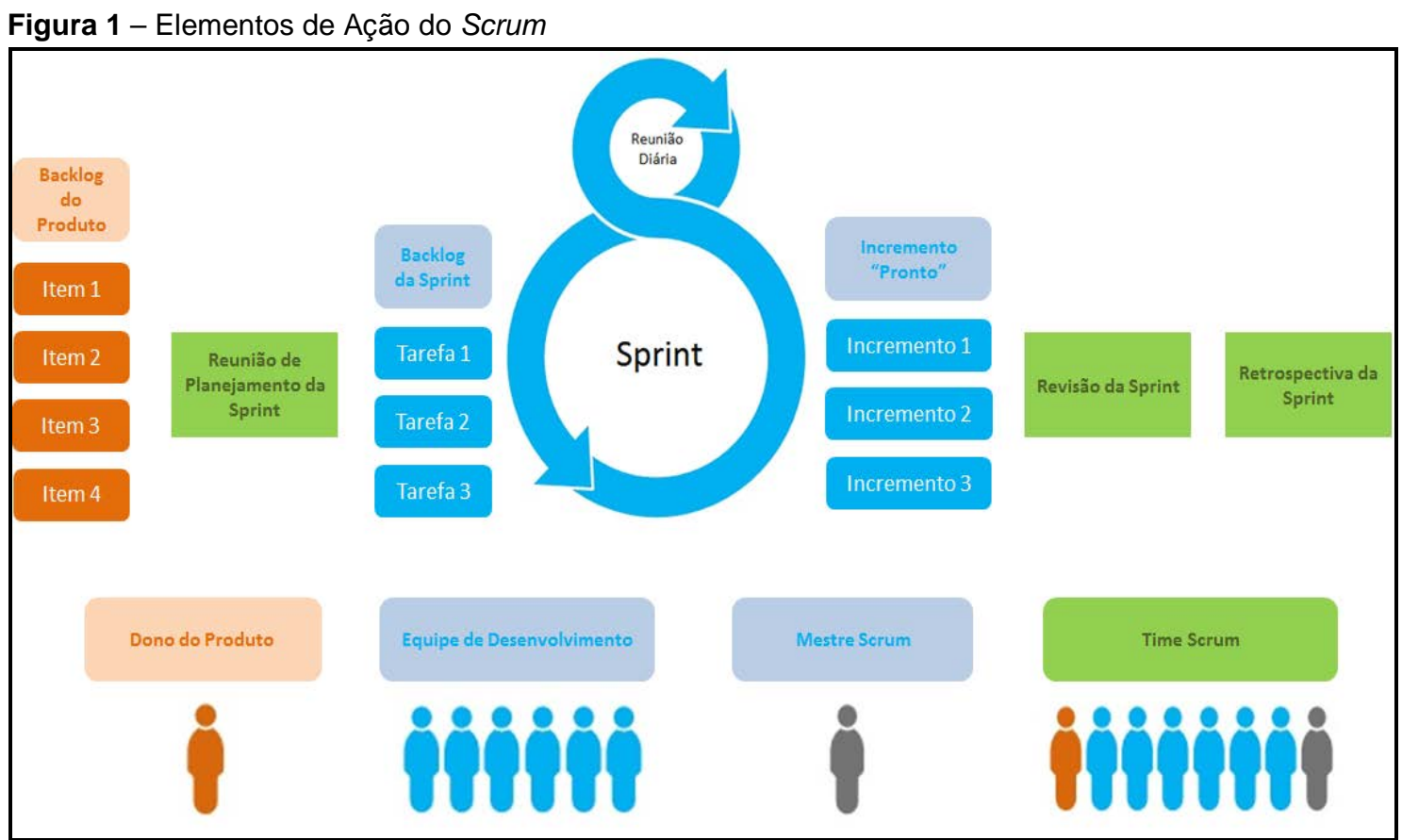

Fonte: Autores ( 2013)

Os personagens: Dono do Produto, Mestre Scrum, Equipe de Desenvolvimento e o Time Scrum se relacionam com os elementos do Scrum (eventos e atributos); Estas relações estão caracterizadas pelos mesmos tons de cores (verde, azul e laranja).

A Sprint é um período, geralmente de um mês ou menos, de execução das atividades, no qual um atributo ou funcionalidade é criado (incremento) atendendo determinados itens do produto.

O Backlog do Produto é uma lista ordenada de itens sobre o que deve ser necessário no produto. Origem única dos requisitos para qualquer mudança a ser feita no produto.

Durante todo o desenvolvimento realizam-se Reuniões de Planejamento da Sprint, que visam selecionar os itens de maior prioridade tratando-os como tarefas a serem entregues no final da Sprint. Deve-se responder as seguintes questões:

1. O que será entregue como incremento da próxima Sprint? 
2. Como será realizado o trabalho necessário para entregar este incremento?

A reunião dará origem ao Backlog da Sprint que é um conjunto de tarefas que atendem aos itens selecionados para a Sprint, juntamente com o plano de entrega do incremento do produto.

Reuniões Diárias, geralmente de 15 minutos, são realizadas para que a Equipe de Desenvolvimento possa sincronizar as atividades e criar um plano para as próximas 24 horas. Durante esta reunião as principais questões são:

1. O que foi completado desde a última reunião?

2. O que será feito até a próxima reunião?

3. Quais os obstáculos que estão no caminho?

Após a Sprint ocorre a Reunião de Revisão da Sprint, que apresenta e inspeciona as atividades concluídas e adapta o Backlog do Produto se necessário. A Reunião de Retrospectiva da Sprint, é a oportunidade final para o time Scrum inspecionar a si próprio e criar um plano de melhorias a serem aplicadas na próxima Sprint.

Time Scrum é formado de personagens, dos quais: O Dono do Produto, que é o responsável por maximizar o valor do produto e do trabalho da equipe de Desenvolvimento. A Equipe de Desenvolvimento, que consiste de profissionais que realizam o trabalho de entregar ao final de cada Sprint um incremento produto. E o Mestre Scrum, aquele que irá garantir que o projeto seja entendido valendo-se das regras do Scrum.

Destaca-se a importância do aprendizado e comprometimento dos envolvidos no decorrer do programa. Busca de patrocínio e estímulo a colaboração entre diferentes times (LONG e STARR, 2008).

MARCHI e GROUVE (2009) ressaltam que o Scrum oferece a equipe uma maior destreza na previsibilidade das etapas subsequentes ao projeto, principalmente através do pelo auxílio visual de estimativas gráficas sobre o desempenho da equipe, geralmente aliados a estes estão os gráficos burndown e burnup. 
O gráfico burndown mostra o quanto resta de iteração durante aquela fase do projeto (Sprint), é usada como principal ferramenta de acompanhamento da iteração; também fornece acompanhamento da produtividade e é um ferramental para a coleta de dados para as retrospectivas. Como mostrado na Figura 2a o eixo $X$ é temporal, pode ser horas de trabalho, dias, semanas ou pontos; já o eixo $Y$ representa as tarefas, pode ser também expresso em dias, horas, semanas ou Sprints.

Figure 2a - Gráfico Burndown

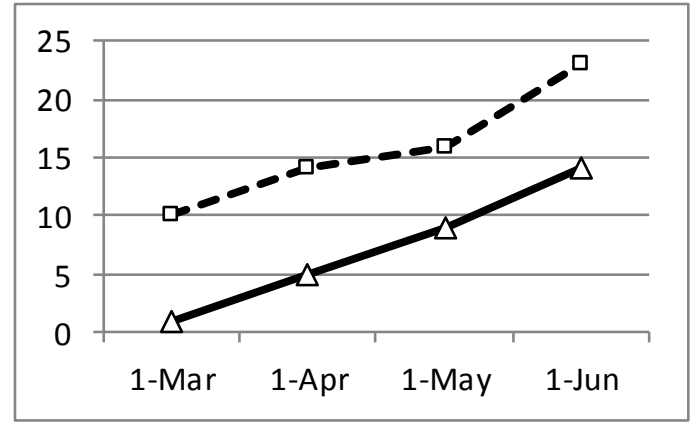

Figure 2b - Gráfico Burnup

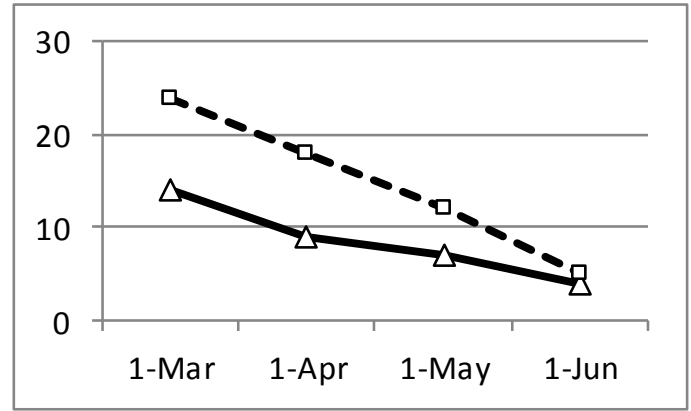

O burndown revela dados importantes sobre a carga de trabalho do time, tais como, andamento evolutivo e o que pode ser melhorado. Por meio dele pode-se saber qual a situação do projeto com o cronograma (adiantado ou atrasado) para que assim providências sejam tomadas. O gráfico burnup tem uma abordagem mais geral, relativo ao escopo do projeto, Figura 2b. Apresenta as tarefas entregues até atual momento por Sprint a fim de prever se a data de comprimento do projeto será cumprida.

\section{PROCEDIMENTO METODOLÓGICO}

A pesquisa é conduzida com enfoque qualitativo e descritivo, realizada no próprio ambiente de estudo, partindo da realidade levantada nas respostas de entrevistados e passando pela análise dos pesquisadores. A perspectiva descritiva busca a resolução de problemas melhorando as práticas por meio da observação, análise e descrições objetivas, através de entrevistas com peritos para a 
padronização de técnicas e validação de conteúdo (THOMAS; NELSON; SILVERMAN, 2007).

O Procedimento Metodológico contempla três fases distintas:

- Análise do Contexto, utilizando-se revisão bibliográfica e resultado da pesquisa de campo;

- Delineamento do Trabalho de Campo, com a caracterização do método e a construção do instrumento de entrevistas que auxilia no levantamento de dados;

- Trabalho de Campo, que identifica aspectos relevantes a implementação do Scrum.

Figura 3 - Método para construção de modelo de Gestão da Produção

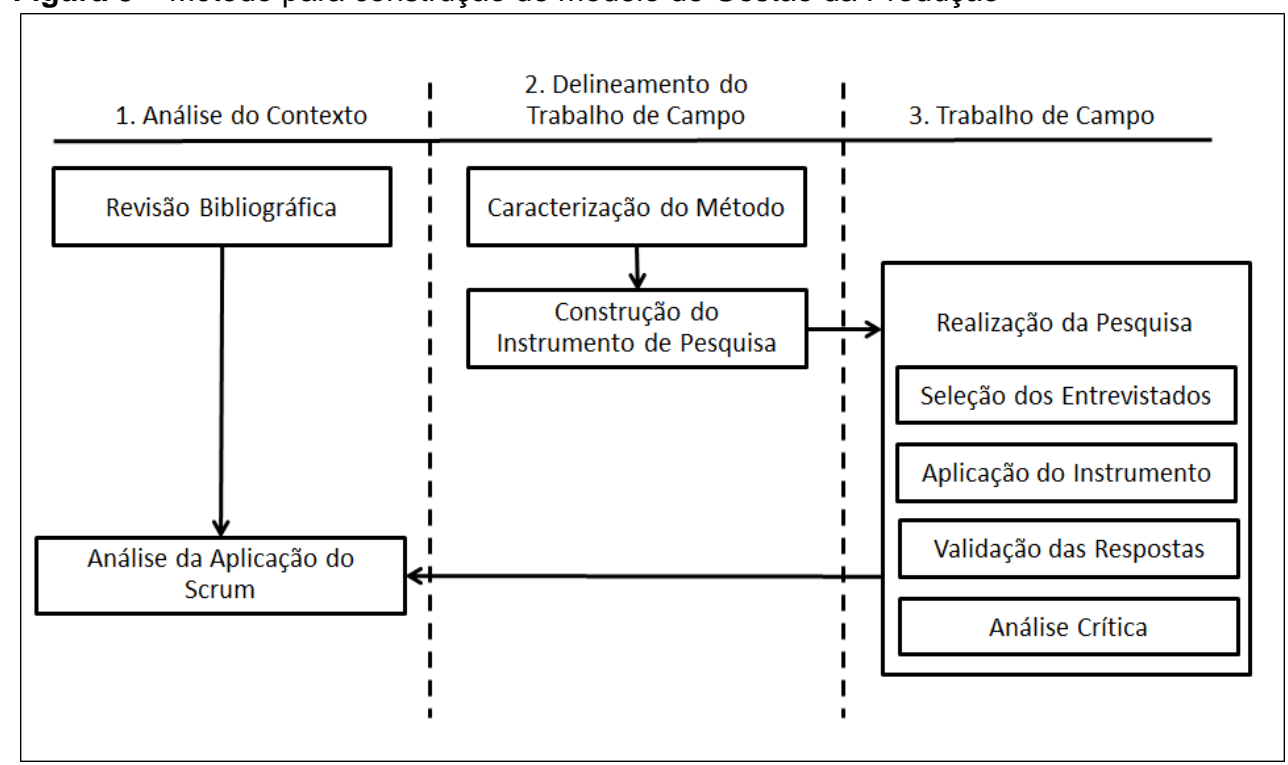

Fonte: Adaptado de Muniz, et al. (2009)

A revisão bibliográfica permitiu um estudo da aplicação do Scrum em diversas áreas, cujas características tornaram possível delinear o trabalho de campo e o instrumento de pesquisa. Foi baseada em artigos obtidos na base ISI Web of Science, no período de 1994 a 2014, usando como palavras-chave Product e Scrum para uma busca por tópicos. O que resultou 83 artigos. O perfil da publicação de artigos sobre o tema é apresentado na Figura 4a. Enquanto que a Figura 4b apresenta a quantidade de citações dos artigos publicados sob mesmas especificações. 
Figura 4a - Quantidade de artigos publicados com Development Product e Scrum

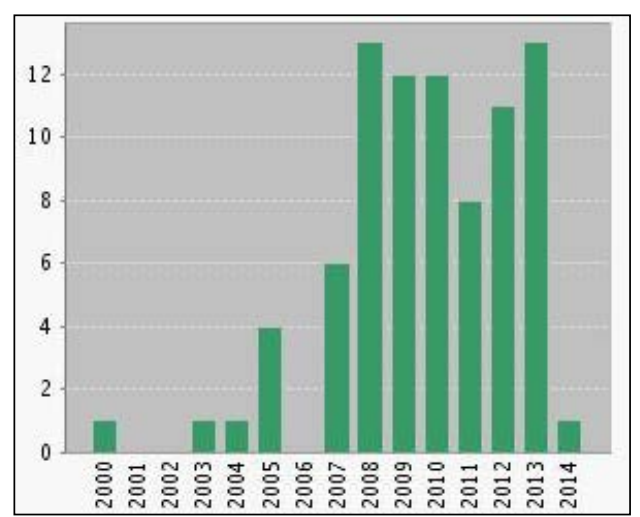

Fonte: WebScience (2014)
Figura $\mathbf{4 b}$ - Quantidade de artigos com as citações Development Product e Scrum

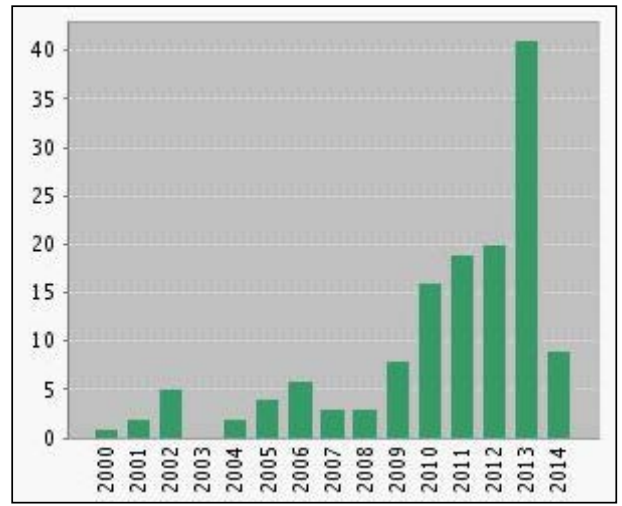

Fonte: WebScience (2014)

Houve um aumento de publicações até 2008, em seguida uma pequena oscilação no número de artigos publicados, o que pode caracterizar um movimento comum da discussão dos temas, ou mesmo uma adaptação, melhor tratamento da união dos temas ao longo destes anos devido a fatores relevantes relacionados nesta época. Entre 2000 a 2007 poucos artigos foram publicados tendo início expressivo apenas a partir de 2008. Indica-se também o aumento do número de citações a cada ano, que configura a quantidade de artigos da plataforma que foram utilizados como referências em outros trabalhos.

O número de artigos evidência que o tema tem sido pouco explorado. Foram analisados aqueles de caráter empírico relacionados as categorias: Computer Science, Engineering or Business Economics, Education Educational Research, Automation Control Systems, Operations Research \& Management Science e Mathematics.

No Delineamento do Trabalho de Campo procurou-se compreender a realidade do ambiente estudado, desta forma, necessária a Caracterização do Método e Construção do Instrumento de Pesquisa.

Obteveram-se dados descritivos mediante contato direto e interativo com a situação alvo. Buscou-se informação diretamente com um grupo de interesse a respeito dos dados que se deseja obter: as características ou opiniões de 
determinado grupo de pessoas indicado como representante de uma populaçãoalvo, utilizando um questionário como instrumento de pesquisa.

Para o Instrumento de Pesquisa, entrevista semi-estruturada, que não segue um roteiro rígido e perguntas padrões. Segundo TRIVIÑOS (1987) a entrevista semiestruturada tem como característica questionamentos básicos que são apoiados em teorias e hipóteses surgidas a partir das respostas dos informantes.

A terceira etapa foi a Realização do Trabalho de Campo, selecionando-se a empresa e respectivo setor de atividade. Após contato e proposta de trabalho, promoveu-se a confiança entre um representante da empresa e o pesquisador, estabelecendo seu papel e responsabilidade com a informação. Em seguida, solicitou-se a autorização para uso acadêmico das respostas obtidas em entrevista.

$\mathrm{Na}$ Seleção de Entrevistados, uma amostra não probabilística de conveniência e julgamento. Segundo REA e PARKER (2002) este tipo de amostragem caracteriza uma seleção na presumida semelhança com a população útil e na sua disponibilidade imediata. A equipe deste setor de Ensaios era composta por 12 integrantes, dos quais, 5 foram escolhidos. O perfil dos entrevistados encontram-se no Quadro 1.

Quadro 1 - Perfil dos Entrevistados

\begin{tabular}{|c|c|c|c|c|}
\hline & Função & Formação & $\begin{array}{c}\text { Tempo de } \\
\text { empresa }\end{array}$ & Tempo na área \\
\hline E1 & $\begin{array}{l}\text { Engenheiro de } \\
\text { Desenvolvimento } \\
\text { de Produto }\end{array}$ & $\begin{array}{c}\text { Engenharia } \\
\text { Elétrica }\end{array}$ & 2,5 anos & 2,5 anos \\
\hline E2 & $\begin{array}{l}\text { Engenheiro de } \\
\text { Ensaios de } \\
\text { Sistemas }\end{array}$ & $\begin{array}{l}\text { Engenharia } \\
\text { Mecânica } \\
\text { Industrial }\end{array}$ & 10,5 anos & 7 anos \\
\hline E3 & $\begin{array}{l}\text { Engenheiro de } \\
\text { Desenvolvimento } \\
\text { de Produto }\end{array}$ & $\begin{array}{l}\text { Engenharia } \\
\text { Aeronáutica }\end{array}$ & 2 anos & 2 anos \\
\hline E4 & $\begin{array}{l}\text { Engenheiro de } \\
\text { Ensaios de } \\
\text { Sistemas }\end{array}$ & $\begin{array}{c}\text { Engenharia } \\
\text { Mecânica }\end{array}$ & 6 anos & 1,5 anos \\
\hline E5 & $\begin{array}{l}\text { Engenheiro de } \\
\text { Desenvolvimento } \\
\text { de Produto }\end{array}$ & $\begin{array}{c}\text { Engenharia } \\
\text { Elétrica }\end{array}$ & 5 anos & 5 anos \\
\hline
\end{tabular}

A Aplicação do Instrumento e coleta de dados foi realizada via e-mail. Repassado ao setor de trabalho os envolvidos puderam responder aos questionários. Dentre as questões apresentadas:

Revista Produção Online, Florianópolis, SC, v.15, n. 1, p. 278-294, jan./mar. 2015. 
- Quais eram os problemas práticos existentes antes do Scrum?

- O que objetivava este projeto?

- Quais foram as dificuldades de implementação?

- Qual a análise comparativa do seu rendimento pessoal?

- Os resultados foram satisfatórios?

A Validação das Respostas ocorreu pela verificação, análise do conteúdo e relacionamento das respostas com o tema estudado. Findou-se o método com a Análise Crítica concluindo-se assim a Análise da Aplicação do Scrum.

\subsection{Contexto Estudado}

A abordagem dinâmica utilizada pelo setor para o gerenciamento ágil do projeto, assumindo elementos característicos à área, demonstra os seguintes aspectos:

- O Dono do Produto tem um nível tático-hierárquico entre o coordenador integrador e o Diretor da área. Uma posição de liderança administrativa, que exerce a função de gerir conhecimento, produção e pessoas. Exercia influência na organização do Backlog do Produto para melhor atender aos requisitos planejados. Conduzia as tomadas de decisões estratégicas relativas ao setor e desenvolve os membros da equipe os mantendo motivados e delegando tarefas em que são mais úteis.

- O Mestre Scrum (focal point) assumia papel de coordenação da equipe, gerenciamento do Backlog do Produto, remoção de impedimentos e resolução de pendências, agendamento e condução de reuniões. Responsável pelo acompanhamento da campanha através do monitoramento e estimativas; faz uso de gráficos burndowns e burnups para aferir sobre o rendimento da equipe. Ele realiza a integração do projeto com as demais áreas relacionadas (no papel de coordenador integrador).

- A Equipe de desenvolvimento era composta por 12 engenheiros que exercem três papéis: 1. Criação/Revisão das RT's; 2. Execução das RT's e 3. Análise dos Resultados obtidos em testes. Afim de produzir um relatório dos 
resultados nos sistemas hidromecânicos e comandos de voo, analisar e submeter a aprovação do setor de Engenharia de Produto.

Relativo aos atributos:

- A Campanha de testes se limitou a ter uma única Sprint. Período em que os testes são criados, revisados e analisados. Havia um plano projetado e flexível que guia o trabalho executado e o escopo de ação nos casos de testes, e eram clarificados e renegociados para atender metas e propostas da área, a partir de reuniões da Sprint, reuniões diárias e comunicação aberta. Um software desenvolvido pela área agendava estas reuniões e gerenciava a campanha de testes.

- O Backlog do Produto era físico, disposto em um quadro de fácil visibilidade a todos os relacionados (Task Board). Apresentava itens que dos sistemas testados. Por meio deles era possível criar e executar tais RT's e recebiam os seguintes status de classificação em colunas: Draft, Reproved, Pending Checking e Problems. $\mathrm{E}$ as linhas compostas pelos elementos hidromecânicos e de comandos de voo: Architecture, Rudder, Elevator, spoiler, aileron, Flap e Hstab. Linhas e colunas se relacionavam através das RT's, particularmente dispostos em post-its.

\section{RESULTADOS ANALISADOS}

Os entrevistados indicaram problemas antes da aplicação do Scrum na área. Dentre eles foram relatados a falta de visibilidade do processo e das pessoas responsáveis pelas atividades; dificuldade de acompanhamento do ciclo processual, sua monitoração, avaliação e estimativas; dos status das atividades: o que carecia ser criado, o que estava em progresso, em revisão, pronto ou que deveria ser cancelado. Dificuldades na identificação de impedimentos e adversidades que implicariam na conclusão das atividades. Atestou-se também para a demora com as tomadas de decisão e mudanças de estratégias, resultado do modo de gerência de projeto que vinha sendo utilizado. 
necessárias durante vários dias. Antes da aplicação do Scrum existia uma dificuldade em ter uma visão geral do andamento da atividade, visto que esta é soma do trabalho de cada componente da equipe. (Entrevistado E1)

Assim surgiu a necessidade de mudar,

Aliada a cultura da empresa em estimular e dispor de uma maior visibilidade do projeto para as pessoas envolvidas - Executores e Gestores. (Entrevistado E2). O objetivo do Scrum era proporcionar maior controle e visualização instantânea do andamento das atividades. Possibilitando maior agilidade do fluxo de trabalho e de aferições no processo. (Entrevistado E3)

Os materiais de referências e instrução, cursos e treinamentos foram oferecidos pela própria empresa, para maior abrangência do tema, suas práticas, eficácia e casos relacionados. Segundo LIVERMORE (2007) muitos são os fatores de controle gerencial envolvido na implementação desta abordagem. É fundamental um bom treinamento da equipe, envolvimento e suporte gerencial, acesso a recursos externos a área e consciência de impacto em outras áreas relacionadas. É necessário estratégia de implementação, exemplos e modelos de referência. Ao fim desta fase, deve abster-se de grandes documentações e modelos para atividades fundamentais e correntes do setor. Mas sim, se apoiar no conhecimento claro e ágil.

O objetivo do Scrum em nossa seção era facilitar a visualização do andamento da atividade instantaneamente por qualquer pessoa, componentes do grupo ou liderança, sem que fosse necessário o acesso a planilhas Excel na rede, ou qualquer outro método (Entrevistado E1). Visava tornar mais eficiente o processo de revisão e criação de procedimentos de ensaio (Entrevistado E2). Dar visibilidade e agilidade do controle das atividades e relacionar os responsáveis pelas entregas. (Entrevistado E4)

Durante a implementação novos empecilhos foram constatados. Primeira houve a dificuldade em mostrar aos envolvidos os benefícios deste tipo de acompanhamento, para remover a ideia de se tratar de um ferramental de medida, de avaliação do desempenho individual, mas sim de um modelo de estímulo, de rendimento conjunto, mostrando diretrizes do projeto e autoconhecimento da equipe envolvida na campanha.

Na minha opinião, tivemos dificuldade nos seguintes pontos:

- falta de um local com boa visibilidade a todos os integrantes do grupo para instalação do Task Board;

- falta de um integrante do grupo, para atuar como mantedor e responsável pelo Scrum, fazendo a validação dos status mostrados no quadro;

- falta de compromisso de alguns em manter suas tarefas atualizadas no quadro, deixando para atualizar vários post-its de uma só vez. (Entrevistado E1).

Revista Produção Online, Florianópolis, SC, v.15, n. 1, p. 278-294, jan./mar. 2015. 
THERRIEN e LEBEL (2009) alertam sobre manter atento aos problemas, as necessidades de orientação, pessoas mantendo ineficiências e deficiências técnicas que podem evoluir sem serem percebidas. Deve-se conversar sobre o projeto, compartilhar experiências, especialmente se tudo estiver indo bem.

Após o período de adaptação os integrantes se fizeram mais comunicativos e comprometidos com este projeto. Foi relatado ganho durante o acompanhamento da evolução da atividade e metas diária, um melhor conteúdo de informações de evolução e problemas encontrados durante os processos.

Percebi que quando o Scrum era utilizado a equipe trabalhava mais focada, pois podíamos visualizar claramente nosso objetivo. Percebi certo aumento na minha produtividade. (Entrevistado E1). A visualização de todo o processo ajudou a manter o foco na atividade e "atacar" os pontos que visualmente mostravam maior deficiência. Com isso o meu rendimento aumentou consideravelmente. (Entrevistado E3). Meu rendimento aumentou pelo menos uns $40 \%$ (Entrevistado E5).

Obteve-se a informação de que o número real acumulado de RT's analisadas esteve muito próximo do número planejado acumulado de RT's durante toda a campanha. Os valores planejados seguem uma curva retilínea ascendente durante toda a campanha, porém cada RT requer um tratamento distinto, com diferentes horas despendidas para execução e análise.

Houve momentos onde procedimentos se mantiveram constantes, requisitaram maior tempo de trabalho para determinada RT. As possíveis paralizações e constâncias na Sprint podem ser previstas juntos do auxílio de story points nos casos de testes, podendo-se prever situações que levem maior ou menor tempo de trabalho. Os story points são previstos pelo Scrum como um modo de priorizar itens, tarefas, atribuindo a estes, graus de importância. Essas atribuições, geralmente representadas por valores numéricos, são uma estimativa do esforço necessário para realização da tarefa. Como ressaltado por MARCHI e GROOVE (2009) quando a empresa Siemens (Illinois, USA - 2009) passou a utilizar a abordagem Scrum em seus projetos, a aplicação de story points visava inferir sobre a velocidade da equipe. Desta forma, os roteiros de testes poderiam trazer estimativas de homem/hora para execução de testes, ou mesmo apenas, uma sinalização de tempo despendido ou esforço requerido para sua execução. Sinalização que pode ser útil no planejamento de delimitação de tarefas a equipe de desenvolvimento, de forma harmoniosa, sem estimular o stress competitivo entre Revista Produção Online, Florianópolis, SC, v.15, n. 1, p. 278-294, jan./mar. 2015. 
componentes da equipe, mas sim, delegação de atividades com base em métricas obtidas.

Este controle poderia também ser benéfico para a Sprint. Com descrito anteriormente, a campanha de desenvolvimento operava com um único Sprint, eficiente, por se tratarem de elementos integráveis, dependentes e da necessidade de visão global do encadeamento do sistema. Contudo, muitas das referências apresentam casos com mais de um Sprint, especialmente para aquelas subsequentes e com certo grau de similaridade. Logo, elementos de avaliação de campanhas passadas poderiam auxiliar no planejamento de campanhas futuras.

O desafio enfrentado durante o ciclo do Sprint é qualificar quantos itens e tarefas podem ser completadas com sucesso durante este período. Baseado no histórico das Sprints pode-se aferir o quão veloz uma equipe desenvolve os incrementos e completa os itens, assim desenvolver estimativas que melhorem o progresso do projeto (GREGORIO, 2012).

A iniciativa auxilia na auto-organização da equipe, que segundo JUDY e KRUMINS-BEENS (2007), é necessário para tornar a equipe auto direcionável compartilhar disciplina e responsabilidade para assim ir além da execução técnica, possibilitando pensar no problema de forma mais ampla e profunda, surpreendendo a si próprio com oportunidades e soluções inventivas.

O que diz respeito a qualidade, o assunto foi ressaltado pelo entrevistado E1, segundo ele o Scrum pode gerar um decréscimo na qualidade, em detrimento da redução de tempo. Condições estas que devem ser acompanhadas e monitoradas durante os ciclos, discutidas em reuniões e sugeridas soluções. Para MARCHI (2009), o Scrum diz que não podemos esperar por qualidade cortando metas de qualidade, mas que devemos prezar e ganhar a confiança dos envolvidos sendo abertos, abertos para os resultados obtidos em campanhas e de performances da equipe.

\section{CONCLUSÕES}

A aplicação da abordagem ágil Scrum no gerenciamento de projetos trouxe bons resultados à área de Ensaios de Sistemas Hidromecânicos e Comandos de Voo, posteriormente, às divisões relacionadas e metas da organização. Alcances de

Revista Produção Online, Florianópolis, SC, v.15, n. 1, p. 278-294, jan./mar. 2015. 
natureza organizacional da gerência e equipe, maior eficiência de processamento e conclusão de metas próximo do previsto foram alcançados. O Scrum trouxe transparência, pois investiu em maior visibilidade dos aspectos significativos do processo para todos aqueles relacionados. Auxiliou em inspeções e monitoramento de resultados, promovendo acompanhamento e orientação do processo em direção ao objetivo e detectando indesejáveis variações e empecilhos durante a campanha de testes. Destaca-se o caráter flexível do Scrum, já que a partir de uma inspeção, constatado desvio de processo para fora dos limites aceitáveis, as etapas de ações podem ser alteradas, adaptando-se regras, atribuições ou mesmo personagens, no intuito de ajustar o processo ou material a fim de minimizar mais desvios.

Como futuras direções de pesquisas sugere-se realizar um trabalho complementar, aplicando o conceito de story points ou qualquer outra sinalização de estimativa homem/hora para execução dos testes, nos roteiros de testes. Possibilitando uma melhor inferência do desenvolvimento da campanha. Assim, monitorar e estimar a evolução da equipe, objetivando melhores índices de produtividade e rapidez na conclusão de metas.

Sugere-se melhor a acessibilidade do Task Board. Substitui-lo, ou mesmo complementa-lo, através de uma plataforma digital ou Software que realizasse a mesma função, possibilitando ainda atualizações e gerenciamento através da rede. Esta ferramenta digital traria maior mobilidade e coordenação do Task Board, porém, perderia nos quesitos visibilidade e comunicação aberta.

\section{REFERÊNCIAS}

ACHARYA, S.; BURKE, D. Incorporating gaming in software engineering projects: case of rmu monopoly. International multi-conference on society, cybernetics and informatics, v.1, p.193-198, 2008.

ARMOSTRONG, G.; KOTLER, P., Princípios de marketing. São Paulo: Person Prentice Hall, 2007.

ANTONI, V. L. Orientação para o mercado e performance: Uma Proposta de Modelo, preditivo para o ensino superior. Passo Fundo: Universidade de Passo Fundo, 2004.

CAMPOS, V., F. Gerenciamento pelas diretrizes. Belo Horizonte: Universidade Federal de Minas Gerais, 1996. 
CARVALHO; VASONCELOS DE MELO, B.; PEREIRA, C. H. Implementation of Scrum agile methodology in software product Project in a small technology-based company. Gestão \& Produção, v.19, n.9, p.557-573, 2012

COUTINHO, C.; CHAVES, J. O Estudo de Caso na Investigação em Tecnologia Educativa em Portugal. Revista Portuguesa de Educação. v.15, n.1, p.221-244, 2002.

DAMIANI, J. H. S. A Nova Face da Gerência de Produtos - O Projeto do Avião ERJ-170 na Embraer, Revista da ESPM. v.8, n.2, p.89-95, 2000.

FLEURY, A.C.C.; MELLO, C.H.P.; NAKANO, N. D.; TURRIONI, B. J.; HO, L., L.; MIGUEL, P. A. C.; NETO, M., R.; MARTINS, R. A.; PUREZA, V.; LIMA, E. P.; SOUZA, R.; COSTA, S. E. $G$. Metodologia de pesquisa em engenharia de produção e gestão de operações. Rio Janeiro: Elsevier, 2010.

FONSECA, J. J. S. Metodologia da pesquisa científica. Ceará: Editora Universidade Estadual do Ceará, 2002.

GREGORIO, D. D. How the Business Analyst Supports and Encourages Collaboration on Agile Projects. IEEE International Systems Conference. p.24-27, 2012.

GRIMHEDEN; EDIN, M. Can agile methods enhance mechatronics design education? Mechatronics, v.22, n.8, p.967-973, 2013

HUANG, P. M., KNUTH, A. A., KRUEGER, R.O., GARRISSON-DARRIN, M.A. Agile Hardware and software Systems Engineering for Critical Military Space Applications. Conference Sensors and Systems for Space Applications V, v.8385, n.83850F, 2012

JAKOBSEN, C. R. e JOHNSON, K. A. Mature Agile with a Twist of CMMI. Agile 2008 Conference. p.212-217, 2008.

JUDY, K. H. e KRUMMINS-BEENS, I. Ript ${ }^{\mathrm{TM}}$ : Innovation and Collective Dono do Produtoship. Agile 2007 Conference, p.316-323, 2007.

KETTUNEN, P. Adopting key lessons from Agile Manufacturing to agile software product development - A comparative Study. Technovation, v.29, n.6-7, p.408-422, 2009. http://dx.doi.org/10.1016/j.technovation.2008.10.003

KOTLER, P. Administração de marketing. São Paulo: Prentice Hall, 2000.

KOTLER, P. KELLER, K. L., Administração de marketing. São Paulo: Pearson Hall, 2012.

KOTLER, P.; ARMSTRONG, G. Princípios de marketing. São Paulo: Prentice Hall, 2004.

LI, C.; Van Den AKKER, M.; BRINKKEMPER, S.; DIEPEN, G. An integrated approach for requirement selection and scheduling in software release planning. Requirements Engineering. v.15, n.4, p.375-396, 2010. http://dx.doi.org/10.1007/s00766-010-0104-x

LIVERMORE, J. A. Factors that impact implementing an agile software development methodology. IEEE SoutheastCon 2007. v.1-2, p.82-86, 2007.

LONG, K. e STARR, D. Agile supports improved culture and quality for healthwise. Agile 2008 Conference, p.160-165, 2008. 
MARCHI, M. e GROVE, B. Weaponized Scrum. Agile 2009 Conference, p.107-112, 2009.

MANZINI, E. J. A entrevista na pesquisa social. Didática. v.26/27, p.148-158, 1990/1991

MAXIMIANO, A. Administração de Projetos - Como Transformar Ideias em Resultados. São Paulo: Atlas, 2002.

MAY, T. Pesquisa social: questões, métodos e processos. Porto Alegre: Artmed, 2004.

MENCKE, R. A Product Manager's Guide to Surviving the Big Bang Approach to Agile Transitions. Agile 2008 Conference. p.407-412, 2008.

MOE, N. B.; AURUM, D. T. Resyster: A Hybrid Recommender system for Scrum team roles based on Fuzzy and Rough sets. Information and Software Technology. v.54, n.8, p.853865, 2012. http://dx.doi.org/10.1016/j.infsof.2011.11.006

MUNIZ, J. Modelo conceitual de Gestão de Produção baseado na Gestão do Conhecimento: um estudo no ambiente operário da indústria automotiva. Tese (Doutorado em Engenharia de Mecânica). Faculdade de Engenharia de Guaratinguetá, Universidade Estadual Paulista. Guaratinguetá, 2007.

NEVES, J. L. Pesquisa Qualitativa: Características, Usos e Possibilidades. Caderno de Pesquisas em Administração. v.1, n.3, 1996.

REA, L. M.; PARKER, R. A. Metodologia de pesquisa: do planejamento à execução. São Paulo: Pioneira Thomson Learning, 2002.

ROTTIER, P. e RODRIGUES, V. Agile Development in Medical Device Company. Agile 2008 Conference. p.218-223, 2008.

SCHWABER, K.; SUTHERLAND, J. The Scrum Guide: The Rules of The Game. 2011 http://www.scrum.org

SINGH, M. U-Scrum: An Agile Methodology for Promoting Usability. Agile 2008 Conference. p.555-560, 2008.

TAKEUSHI, H.; NONAKA, I. The new new product development game. Harvard Business Review Magazine, 1968.

THERRIEN, I.; LEBEL, E., From Anarchy to Sustainable Development: Scrum in Less than Ideal Conditions. Agile 2009 Conference. p.289-294, 2009.

THOMAS, J. R.; NELSON, J. K.; SILVERMAN, S. J. Métodos de pesquisa em atividade física. Porto Alegre: Artmed, 2007.

TRIVIÑOS, A. S. Introdução à pesquisa em ciências sociais. São Paulo: Atlas, 2008

TSAI, W.; WU, W.; HUGNS, M. N. Cloud-Based software Crowdsourcing. IEEE Internet Computing. v.18, n.3, p.78-83, 2014. http://dx.doi.org/10.1109/MIC.2014.46

UY, E.; ROSENDAHL, R. Migrating from SharePoint to a Better Scrum Tool. Agile 2008 Conference. p.506-512, 2008.

VLAANDEREN, K.; JANSEN, S.; BRINKKEMPER, S.; JASPERS, E.; The agile requirements refeinery: Applying Scrum principles to software product management. Information and 
Software Technology. v.53, n.1, p.58-70, 2011.

http://dx.doi.org/10.1016/j.infsof.2010.08.004

WILLEKE, E. R. Inkubook.com: A tale of five process. Agile 2009 Conference, p.156-161, 2009.

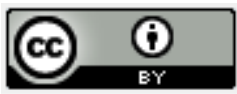

Artigo recebido em 17/04/2014 e aceito para publicação em 12/11/2014

DOI: http://dx.doi.org/ 10.14488/1676-1901.v15i1.1777 